\title{
Studying the Mental Health Status of Soldiers and Related Factors: A Descriptive Study
}

\author{
Fatemeh Mirzaie $^{1}$, Hosien Shahdadi ${ }^{2}$, Esmat Bandani ${ }^{3}$ \\ ${ }^{1}$ Bs Midwifery Student, Student Research Committee, Nursing Department, Zabol University of medical science, Zabol, IR Iran \\ ${ }^{2}$ Nursing Department, Zabol University of medical science, Zabol, IR Iran
}

${ }^{3}$ BS Nurse, Student Research Committee , Midwifery Department, Zabol University of medical science, Zabol, IR Iran

\begin{abstract}
Introduction: Mental health is one of the pillars of health and a prerequisite for a useful, effective, and satisfying individual life. Since the main body of the Armed Forces consists of Iranian youth, the present research aimed to study the mental health status of soldiers. Methodology: The present research was a descriptive, cross-sectional study. The statistical population included 100 soldiers who were selected by the total enumeration method. The required data and information were collected using the standard 28 -item General Health Questionnaire, known as Goldberg's GHQ28. The obtained data and information were analyzed using descriptive tests and Chi-square in SPSS-16 software. Results: The mean age of soldiers was $22.6 \pm 1.9$ (years). Evaluation of mental health in four dimensions in the studied population of soldiers showed that the mean score of mental health is 55 out of 112. In addition, the mean score of physical health, anxiety and sleep disorders, social dysfunction, and depression were obtained 13 $\pm 4.7,14 \pm 5.8,15 \pm 4.9$, and 13.1 \pm 6 (out of 28), respectively. According to Pearson test, there is a significant relationship between mental health and years of service $(p<0.001)$. In addition, the results of t-test showed that there is a significant relationship between marital and residential status and general health $(p<0.001)$. The results of ANOVA suggested no significant relationship between mental health and education degree. Discussion and conclusion: The mean score of mental health indicates a moderate level of mental disorder. According to the results of this study, the officials of mental health in the armed forces are recommended to provide counseling and psychological services for soldiers and also develop a database for mental health of soldiers for timely prevention, diagnosis, and treatment of vulnerable people.
\end{abstract}

Keywords: Mental; Health; Soldiers

\section{Introduction}

Mental health is one of the pillars of health and a prerequisite for a useful, effective, and satisfying individual life. Improving the mental health of a community and especially its effective groups is required for the dynamism, growth, and advancement of that community 1 . Mental health is a balanced manifestation of personality and emotional beliefs which enables one to live in a harmony with others. A person with a good level of mental health owns three major features including comfort, correct feeling about others, and the power to meet the needs of life ${ }^{2}$. Today, mental problems and disorders such as anxiety and depression have increased in many segments of society, including the soldiers (the nature of their job) and annually impose high costs on the health sector of countries ${ }^{3}$. In a study on Norwegian soldiers, D Vancampfort showed that $48 \%$ of them suffer from mental disorders. This high rate of prevalence was attributed to situational factors in this country ${ }^{4}$. The results of a study conducted by Shahbazi et al. entitled "Studying the mental health and self-esteem among the first-year and last-year students of a military school" showed that the frequency of anxiety, sleep disorders, and depressive symptoms is higher among the first-year students then the last-year ones ${ }^{5}$. The results of the study of CW Hoge, entitled "Mental health problems, use of mental health services, and attrition from military service after returning from deployment to Iraq or Afghanistan", indicated that $9.2 \%$ of all subjects are mentally disturbed. ${ }^{6}$ AC Iversen et al. carried out a study entitled "Risk factors for post-traumatic stress disorder among UK Armed Forces personnel" in two phases of 20042006 and 2007-2009. Their findings revealed that the level of mental health is less in military forces and the prevalence of mental disorders among them has been higher in the period 2004-2009 ${ }^{7}$. The study of Hoff et al. entitled "Mental health of soldiers in Australia" showed that $22 \%$ of Australian soldiers are mentally disturbed ${ }^{8}$. Their results showed that frequency of mental disorders among the soldiers is $23-40 \%$ and mental disorders are more prevalent among the soldiers participated in the Iraq war than those who were in Afghanistan ${ }^{8}$. Other studies conducted in Iran show different prevalence rates of mental disorder in Iranian society. The study conducted by Ganji et al. showed that $14 \%$ of referrals for medical exemptions is due to mental disorders ${ }^{9}$. Studies indicate that soldiers suffer from mental disorders are more likely to attempt a suicide ${ }^{10,11}$. A study conducted by Khademolhosseini et al., entitled "The impact of military training on mental health cadets", showed that military training has no effect on the mental health of soldiers ${ }^{12}$. Other studies also have shown the prevalence of mental disorders in other communities. A study on mental health of women in Kashan showed that $40 \%$ of them are suffering from mental health problems ${ }^{13}$.

However, since the Armed Forces id the most populous organization of Iran after Education Organization and considering the organizational structure of the army which is always associated with various missions, a lot of pressure is often imposed on the military people. On the other hand, the main body of the Armed Forces consists of Iranian youth and if this group lacks the necessary physical and mental abilities for dealing with their tasks and problems, the efficiency of the armed forces and the security of the country will damage and, consequently, national and international social relations will be exposed to threat. 


\section{International Journal of Science and Research (IJSR) \\ ISSN (Online): 2319-7064}

Index Copernicus Value (2013): 6.14 | Impact Factor (2015): 6.391

Therefore, the present research aims to study the mental health status of soldiers in order to propose some solutions for improving the mental health level of this population.

\section{Methodology}

The present research was a descriptive, cross-sectional study. The statistical population included all soldiers of the Army of the Guardians of the Islamic Revolution and the Law Enforcement Force of Islamic Republic of Iran who were doing their military service in Nikshahr Military Base, 150 of whom were selected as the sample using the total enumeration. The required data and information were collected using the standard 28-item General Health Questionnaire, known as Goldberg's GHQ28 ${ }^{14}$.

General Health Questionnaire has been repeatedly used in domestic and foreign studies for evaluating the mental health of different groups such as students, employees, etc. 15,16 . This 28 -item questionnaire consists of 4 categories ( 7 items for each category) including somatic symptoms, anxiety and sleep disorders, social dysfunction, and depression. A 4-option scales (No, a little, high, and very high) was determined for the questionnaire and the scores between zero and three were given to each option. Therefore, the score of each category may vary from 0 to 21 . The minimum and maximum total score of this questionnaire is 0 and 82 . Obtaining a score in the ranges of $0-22,23-40,41-60$, and 61-84 were indicative of lack of mental disorders, mild mental disorders, moderate mental disorders, and intense mental disorders, respectively. The remarkable thing about this questionnaire is that obtaining a high score indicates more pathological symptoms or, in other words, lower general health, while lower scores are indicative of minimum pathological symptoms and a higher level of general health. After correspondence and coordination with the Bureau of Applied Research of the Law Enforcement Force of Islamic Republic of Iran in Sistan and Baluchistan Province, the soldiers who were doing their military service in the Army of the Guardians of the Islamic Revolution and the Law Enforcement Force of Islamic Republic of Iran in Nikshahr Military Base were randomly selected as the sample. Then, the questionnaires were handed out among them in person and they were asked to fill the out. Soldiers were ensured that all information will remain confidential in order to encourage them to give more concrete answers to questions. The obtained data and information were analyzed using descriptive tests and Chisquare in SPSS-16 software.

\section{Results}

The results of this study showed that the mean age of soldiers was $22.6 \pm 1.9$ (years). In terms of marital status, $82 \%$ of soldiers were single and $18 \%$ were married. Among the studied soldiers, $63 \%, 29 \%$, and $8 \%$ had a high school diploma, a bachelor's degree, and a master's degree, respectively. The average length of service of the studied soldiers was $9.2 \pm 4.5$ months (Table 1). Evaluation of mental health in four dimensions in the studied population of soldiers showed that the mean score of mental health is 55 out of 112. In addition, the mean score of physical health, anxiety and sleep disorders, social dysfunction, and depression were obtained $13 \pm 4.7,14 \pm 5.8,15 \pm 4.9$, and $13.1 \pm 6$ (out of 28), respectively. According to Pearson test, there is a significant relationship between mental health and years of service $(p<0.001)$. In addition, the results of t-test showed that there is a significant relationship between marital and residential status and general health $(\mathrm{p}<0.001)$. The results of ANOVA suggested no significant relationship between mental health and education degree $(p>0.05)$.

Table 1: Demographic information

\begin{tabular}{|c|c|c|c|}
\hline \multicolumn{2}{|c|}{ Variable } & Frequency & Percentage \\
\hline Education & High school diploma & 63 & $63 \%$ \\
\cline { 2 - 4 } & Bachelor's degree & 29 & $29 \%$ \\
\cline { 2 - 4 } & Master's degree & 8 & $8 \%$ \\
\hline Marital status & Single & 82 & $82 \%$ \\
\cline { 2 - 4 } & Married & 18 & $18 \%$ \\
\hline
\end{tabular}

Table 2: Mental health in different dimensions

\begin{tabular}{|c|c|}
\hline Dimensions & Mean \pm SD \\
\hline Physical & $13 \pm 4.7$ \\
\hline Anxiety and sleep disorders & $14 \pm 5.8$ \\
\hline Social & $15 \pm 4.9$ \\
\hline Depression & $13.1 \pm 6$ \\
\hline
\end{tabular}

\section{Discussion}

In recent years, much research has been done in the field of mental health, but few ones have been carried out on the military forces. The results of mean score of mental health indicate a moderate level of mental disorders prevalence (50\%) among the studied sample. In contrast, Mousavi et al. showed that $42.6 \%$ medical students and $37.5 \%$ of paramedical students are experiencing mental health problems ${ }^{17}$. In separate studies conducted by Shariati ${ }^{18}$ and Tavakolizadeh ${ }^{19}$, prevalence of mental health disorders was reported to be $42.6 \%$ and $27.1 \%$ among the university student. These figures are less than those obtained on the soldiers' population in this study which can be due to the type of studied population and higher level of stress during the military service. As the study conducted by Marzanabadi et al. showed $67 \%$ of military personnel have a high level of stress and $11 \%$ of them have a severe stress level ${ }^{20}$. The results of studies conducted on mental health in the community of women who are the head of their household or women who have a child with mental disorder show that the prevalence of mental health problems in these two populations ( $61 \%$ and $77 \%$, respectively) is higher than the soldiers' population ${ }^{21,22}$. Overseas studies show the high prevalence of mental health disorders among soldiers. The study of Han Wei on the mental health and life quality of Taiwanese soldiers showed that $57.4 \%$ of soldiers are experiencing mental health problems ${ }^{23}$. Figure is higher than the figure for Iranian soldiers [27, 30, and 34]. A study on the relationship of satisfaction with major with mental health and academic achievement among students of Arak University of Medical Sciences showed that the mean score of mental health in the whole population is in the range of mild disorder ${ }^{24}$. In another study carried out by Dr. Mirzamani, entitled "Lifestyle of military personnel of the Army of the Guardians of the Islamic Revolution", showed the mean score of mental health is 19.1 in this population that is significantly different from the results of above study 25. Therefore, since higher scores on the General Health

\section{Volume 5 Issue 8, August 2016}

\section{www.ijsr.net}

Licensed Under Creative Commons Attribution CC BY 


\section{International Journal of Science and Research (IJSR) \\ ISSN (Online): 2319-7064}

Index Copernicus Value (2013): 6.14 | Impact Factor (2015): 6.391

Questionnaire mean a lower level of mental health, it can be concluded that with regard to the specific circumstances and different stress during military that surround a person, such results are not unexpected. This can be due to several reasons such as longing, separation from family, and being worried about the family status. Military service around the world is associated with mental pressures, physical hazards, separation from family, and living in harsh conditions. The statistical analysis showed no significant relationship between age and mental health, while Dehbashi et al. reported that the score of general health increases with the increase in the age of subjects. In other words, the desirable level of mental health reduces as a person ages. The study findings also showed that there is a significant relationship between developmental status of general health. Increased rates of psychological symptoms in married people, compared to the single, is unlike the common epidemiology of diseases, because marriage typically reduces the rate of psychological symptoms and celibacy increases them [11]. However, reverse results were obtained in the present study which can be due to several reasons such as being aware of their wife and fear of her conditions. The findings of Ashtiani confirm most of the results obtained in the present study. In the present study, no significant relationship was found between mental health and education, while Dehbashi et al. found a significant relationship between these variables ${ }^{26}$. Shahbazi also reported the same relationship in his study ${ }^{5}$. One of the reasons for this difference may be the point that most of soldiers participated in this study $(63 \%)$ had a high school diploma. Many studies show that the prevalence of mental disorders in other populations is less than that of soldiers. The study conducted by Radfard on children of veterans showed that the prevalence of mental disorders among the girls and boys is $36 \%$ and $26.8 \%$, respectively ${ }^{27}$. Another study by Radfard on the rural and urban populations aged 15-24 in 1999 showed that $17.6 \%$ of subjects were suffering from mental health problems ${ }^{27}$.

\section{Conclusion}

Awareness of the mental health status of all military forces and especially soldiers is of great importance, because diseases of military forces are now considered the main cause of military weakness. Since it is not possible to solve this problem alone and it should be done in a collaboration, there should be a serious cooperation between military commanders, psychologists, and psychiatrists. According to the findings of the present study, it can be stated that examination of soldiers in terms of mental health at the beginning of their military services can underlie better life, well-being, and better work of them. Based on the results, the officials of mental health in the armed forces are recommended to take the following measures:

- Providing the conditions for easy contact of soldiers and military personnel with their families

- Providing counseling and psychological services for soldiers

- Considering special facilities for married soldiers and those who are the head their family

\section{Acknowledgment}

We would like to thanks from all participants in this study.

\section{Conflict of Interest}

None declared

\section{References}

[1] Cuthbert BN, Insel TR. Toward the future of psychiatric diagnosis: the seven pillars of RDoC. BMC medicine. 2013;11(1):126.

[2] Townsend MC. Psychiatric mental health nursing: Concepts of care in evidence-based practice. FA Davis; 2014.

[3] Association AP. Diagnostic and statistical manual of mental disorders (DSM-5®). American Psychiatric Pub; 2013.

[4] Vancampfort D, Probst M, Scheewe T, et al. Relationships between physical fitness, physical activity, smoking and metabolic and mental health parameters in people with schizophrenia. Psychiatry research. 2013;207(1):25-32.

[5] Shahbazi M, Vazini taher A. A Survey to the Mental Health and Self-esteem of Freshmen and Seniors at a Military University. Journal of Military Medicine. 2013;15(2):103-110.

[6] Hoge CW, Auchterlonie JL, Milliken CS. Mental health problems, use of mental health services, and attrition from military service after returning from deployment to Iraq or Afghanistan. Jama. 2006;295(9):1023-1032.

[7] Iversen AC, Fear NT, Ehlers A, et al. Risk factors for post-traumatic stress disorder among UK Armed Forces personnel. Psychological medicine. 2008;38(04):511522.

[8] Van Hooff M, McFarlane AC, Davies CE, et al. The Australian Defence Force Mental Health Prevalence and Wellbeing Study: design and methods. European journal of psychotraumatology. 2014;5.

[9] Ganji F. Distribution Rate of Causes of Medical Exemption from Compulsory Service among Shahrekord Conscripts 2001. Journal Mil Med. 2005;6(4):225-231.

[10] Harris EC, Barraclough B. Suicide as an outcome for mental disorders. A meta-analysis. The British Journal of Psychiatry. 1997;170(3):205-228.

[11] Milliken CS, Auchterlonie JL, Hoge CW. Longitudinal assessment of mental health problems among active and reserve component soldiers returning from the Iraq war. Jama. 2007;298(18):2141-2148.

[12] Khademolhoseini S, Najafi S, Ebadi A, Naji M, Rezaee Hajiabadi H, Asgari A. Influence of military training period on cadet students' mental health. Journal Mil Med. 2009;11(2):75-79.

[13] Sepehrmanesh Z. Mental health and its related factors in young women in Kashan City. Iranian Journal of Obstetrics, Gynecology and Infertility. 2009;12(1):3141.

[14] Bridges KW, Goldberg DP. The validation of the GHQ28 and the use of the MMSE in neurological in-patients. 
The British Journal of Psychiatry. 1986;148(5):548553.

[15] Lobo A, Pérez-Echeverría MJ, Artal J. Validity of the scaled version of the General Health Questionnaire (GHQ-28) in a Spanish population. Psychological medicine. 1986;16(01):135-140.

[16] Malakouti SK, Fatollahi P, Mirabzadeh A, Zandi T. Reliability, validity and factor structure of the GHQ-28 used among elderly Iranians. International Psychogeriatrics. 2007;19(04):623-634.

[17] SH.Hosanei , MH.Mosavy The comparative study of health status of medical students and para-medical students trainee. Journal of Gorgan University of Medical Sciences. 2004;6(1):101-107.

[18] Shariati M, Yunesian M, Vash JH. Mental Health Of Medical Students: A Cross-Sectional Study In Tehran Psychological reports. 2007;100(2):346-354.

[19] Tavakolizadeh J, Khodadadi Z. Assessment of mental health among freshmen entering the first semester in Gonabad University of Medical Sciences in 2009-2010. The Horizon of Medical Sciences. 2010;16(2):45-51.

[20] Azad-Marzabadi E., Salimi S. H. Study on Job Stress in a Military Unit. Journal of Military Medicine. 2005;6(4):279-284.

[21] Seal KH, Bertenthal D, Miner CR, Sen S, Marmar C. Bringing the war back home: Mental health disorders among 103788 US veterans returning from Iraq and Afghanistan seen at Department of Veterans Affairs Facilities. Archives of Internal Medicine. 2007;167(5):476-482.

[22] Cunningham-Williams RM, Cottler LB, Compton 3rd W, Spitznagel EL. Taking chances: problem gamblers and mental health disorders--results from the St. Louis Epidemiologic Catchment Area Study. American Journal of Public Health. 1998;88(7):1093-1096.

[23] Chou H-W, Tzeng W-C, Chou Y-C, et al. Psychological morbidity, quality of life, and self-rated health in the military personnel. Neuropsychiatric disease and treatment. 2014;10:329.

[24] Changizy Ashtyani S, Shamsi M, Mohammadbeygi A. Frequency of educational decline and some effective factors of student's opinion in Arak University of Medical Sciences, 2009. Arak Medical University Journal. 2010;12(4):24-33.

[25] S M. Lifestyle of military personnel of the Army of the Guardians of the Islamic Revolution. Ann Mil Health Sci Res. 2005;2(4):443-450.

[26]Dehbash A, Talebi M. Study of mental health in the office employees of the Shahid Khazraei military educational center. EBNESINA. 2008;11(1):11-16.

[27] Radfar Sh., Haghani H., Tavalaei S. A., Modirian E., Falahati M. Evaluation of Mental Health State in Veterans Family (15-18 Y/O Adolescents). Journal of Military Medicine. 2005;7(3):203-209. 